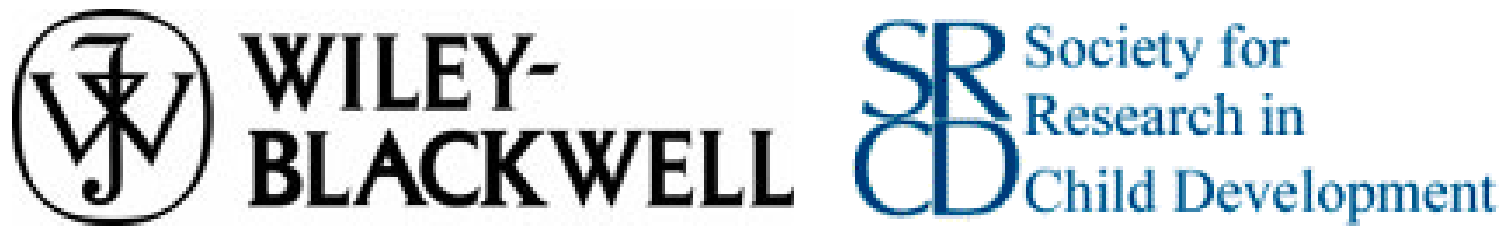

Systematizing Semantic Knowledge: Changes over Time in the Child's Organization of Word Meaning

Author(s): Melissa Bowerman

Source: Child Development, Vol. 49, No. 4 (Dec., 1978), pp. 977-987

Published by: Blackwell Publishing on behalf of the Society for Research in Child

Development

Stable URL: http://www.jstor.org/stable/1128737

Accessed: $2 2 \longdiv { / 0 6 / 2 0 1 0 0 8 : 3 5 }$

Your use of the JSTOR archive indicates your acceptance of JSTOR's Terms and Conditions of Use, available at http://dv1litvip.jstor.org/page/info/about/policies/terms.jsp. JSTOR's Terms and Conditions of Use provides, in part, that unless you have obtained prior permission, you may not download an entire issue of a journal or multiple copies of articles, and you may use content in the JSTOR archive only for your personal, non-commercial use.

Please contact the publisher regarding any further use of this work. Publisher contact information may be obtained at http://www.jstor.org/action/showPublisher?publisherCode=black.

Each copy of any part of a JSTOR transmission must contain the same copyright notice that appears on the screen or printed page of such transmission.

JSTOR is a not-for-profit service that helps scholars, researchers, and students discover, use, and build upon a wide range of content in a trusted digital archive. We use information technology and tools to increase productivity and facilitate new forms of scholarship. For more information about JSTOR, please contact support@jstor.org.

Blackwell Publishing and Society for Research in Child Development are collaborating with JSTOR to digitize, preserve and extend access to Child Development. 


\title{
Systematizing Semantic Knowledge: Changes over Time in the Child's Organization of Word Meaning
}

\author{
Melissa Bowerman \\ University of Kansas
}

\begin{abstract}
Bowerman, Meurss. Systematizing Semantic Knowledge: Changes over Time in the Child's Organization of Word Meaning. Chmld Development, 1978, 49, 977-987. Selected spontaneous errors of word choice made between the ages of about 2 and 5 by 2 children whose language development has been followed longitudinally were analyzed for clues to semantic development. The errors involved the children's occasional replacement of a contextually required word by a semantically similar word after weeks or months of using both words appropriately. Because the errors were not present from the beginning and because correct usage prevailed most of the time, the errors cannot be explained by existing accounts of semantic development, which ascribe children's word-choice errors to initial linguistic immaturity. A plausible alternative account likens the errors to adult "slips of the tongue" in which the speaker, in the process of constructing a sentence to express a given meaning, chooses incorrectly among competing semantically related words. Interpreted in this way, the errors indicate that the process of drawing words into structured semantic systems based on shared meaning components begins much earlier than experimental studies have suggested. They also provide evidence for certain differences between children and adults in the planning and monitoring of speech.
\end{abstract}

A primary method for exploring young children's understanding of word meaning has been the analysis of their spontaneous errors of word choice. The significance of these errors has been debated in the recent literature, and several different hypotheses have been advanced to account for them. In this paper I will present error data that cannot easily be accounted for by any of the existing models and argue that these data provide evidence for the early onset of a process that has been thought not to take place until relatively late in development, the growth of a sense of semantic relatedness among words.

The errors to be discussed were collected from my two daughters, Christy and Eva, whose language development I have followed closely by daily notes and periodic taping from the time of first words (Bowerman 1974, 1976, 1977,1978 , Note 1). The following error illustrates the genre.

Eva, 3-9, to Mother, who is fixing dinner: "Can I have any reading behind the dinner?"
The situational context of this utterance and the subsequent conversation made it clear that Eva wanted to be read to after dinner. Why did she not say "after"? Let us consider some possible explanations.

\section{Existing Hypotheses}

According to Clark (1973), children's errors of word choice reflect incomplete knowledge of the meanings of the incorrectly used words. In her "semantic feature" hypothesis of the acquisition of word meaning, Clark proposed that children at first identify a word with only one or a very few semantic features from the full set of features that constitutes the meaning of the word for adults. Because these first features are very general (e.g., [+ four-legged] for doggie), the child overextends the word-that is, uses it for a broader range of referents than an adult would. Applying Clark's proposal to Eva's error with behind, we might hypothesize that Eva made the error because she had as yet acquired only a rather

Paper presented in the symposium on the Acquisition of Word Meaning, biennial meeting of the Society for Research in Child Development, New Orleans, March 1977 (retitled from "The Reorganization and Consolidation of the Child's Semantic System"). This research was supported in part by grant HD00870 from NICHD. I am grateful to the participants in this symposium for helpful comments on an earlier draft of this paper. Author's address: Bureau of Child Research, University of Kansas, Lawrence, Kansas 66045.

[Child Development, 1978, 49, 977-987. (C) 1978 by the Society for Research in Child Development, Inc. 0009-3920/78/4904-0006\$01.02 


\section{Child Development}

general feature for behind, such as [ + beyond or following (object or event $X$ )]; she had not yet added a more specific feature such as [+ spatial] which would prevent her from using the word in the context of temporal "beyondness."

Several investigators have questioned the claim that children's overextensions are due to an incomplete knowledge of word meaning. Bloom (1973), for example, proposes that overextensions may stem from children's willingness to stretch available words whose meanings they really know to cover new referents for which they do not yet have names. Clark (1975) has revised her earlier hypothesis in light of more recent evidence and now also suggests that at least some overextensions may result from vocabulary limitations rather than underspecified word meanings. Following this account, we could hypothesize that Eva knew the meaning of behind but did not yet know the word after; her use of behind in an "after" situation was induced by a communicative need.

A second account of children's early wordchoice errors that does not assume incomplete knowledge of word meaning has been proposed by Huttenlocher (1974). According to this interpretation, overextensions may occur even when the child knows (i.e., can show comprehension of) the meanings of both the overextended word and the word required by the context. The error takes place, suggests Huttenlocher, because speech production initially places much heavier demands on the child than comprehension. Faced with the need to label a certain referent, the child is unable to retrieve the required word from his memory. Instead, he may retrieve the word in the same semantic domain (e.g., body parts, animals) that is most frequent in the speech he hears. Following Huttenlocher's proposal, we might hypothesize that Eva knew the needed word, after, but was not yet able to retrieve it; behind was more accessible to her because (perhaps) she heard it more frequently.

These various hypotheses differ in important ways, but they all make the basic assumption that errors of word choice stem from the child's initial linguistic immaturity. That is, they all predict that any errors a child is going to make in the use of a particular word should occur early and then drop out, either as the entry for the word in the child's mental lexicon is "filled in," as words are acquired for the referents to which the word was once extended in attacks of communicative need, or as a chronic difficulty in retrieving the needed word for production is eased.

The pattern of word use in the period preceding Eva's error with behind is not consistent with this assumption. Both the overextended word, behind, and the word called for, after, had been in Eva's active vocabulary for many months, and un until the time of the error they had been used semantically and syntactically in a completely correct way, for spatial versus temporal concepts, respectively. This developmental pattern characterized a large number of word-choice errors made by Christy and Eva in the first few years of language acquisition. In every case, the incorrectly used word had previously been used correctly for a period of time ranging from a few weeks to a year or more, and at the time of the error the child had a more appropriate word in her vocabulary and usually used it where it was called for. Some errors were heard only once, like Eva's substitution of behind for after. Other errors were more frequent and systematic, recurring periodically for some time. ${ }^{1}$

\section{Substitution Errors as Evidence for the Recognition of Semantic Similarities among Words}

What accounts for these late-emerging errors? A plausible interpretation is suggested by analyses of adult "slips of the tongue," errors that have been extensively explored for the clues they provide to the speaker's organization and storage of information about language structure and to the steps involved in generating utterances (e.g., Fromkin 1973).

Adult slips of the tongue fall into several categories. The category that is relevant for present purposes is that of errors in which a "target" or intended word is accidentally

1 The corpus of "late" errors under consideration in this paper represents only a subset of word-choice errors collected from these children. Many of their other errors can be interpreted according to hypotheses that invoke linguistic immaturity (e.g., see Bowerman 1976, 1978,
Note 1). 
replaced by one that is semantically related to it. Examples taken from Fay and Cutler (1977), Fromkin (1971), and Nooteboom (1969) include the following:

1. I really like to-hate to get up in the morning.

2. It's at the bottom-I mean-top of the stack of books.

3. The two contemporary, er-sorry, adjacent buildings.

4. Not Thackeray but someone that wrote below Thackeray-before Thackeray.

It has been proposed that errors like these occur because of a minor breakdown in the process of sentence production (Fromkin 1971, 1973, introduction; Laver 1973; Nooteboom 1969). According to this model, the speaker starts with a certain meaning that he wants to communicate. He then must "construct ... a a neurolinguistic program for the expression of the idea. ... This presumably involves the selection from long-term storage of lexical items and grammatical arrangements, together with their associated phonology, by criteria of semantic appropriateness to the expression of the initial idea" (Laver 1973, p. 134). At this stage, more candidate lexical items may be "activated" (Laver 1973, p. 135) than are ultimately selected. The speaker must therefore be able to implicitly evaluate competing alternatives for their appropriateness for expressing a given idea and choose among them. This is ordinarily accomplished without incident. Sometimes, however, a word that is inappropriate, although in the general semantic neighborhood of the desired word, is accidentally selected. The aspects of meaning shared by the target word and the word substituted for it are often formally represented in this model in terms of semantic features common to the speaker's lexical entry for both words.

There are certain important similarities between adult semantically based slips of the tongue and the late-emerging errors collected from Christy and Eva. Most critically, in the case of both adult and child the errors involve words that are usually used correctly. In addition, some of the children's errors were strikingly similar to those made by adults. Compare, for example, Eva's substitution of behind for after with the adult errors 3 and 4 above: all of these violate the distinction between position in space and position in time. These simi- larities suggest that the children's errors, like those of adults, can be interpreted as resulting from an incorrect choice among semantically related words that compete for selection in a particular speech context.

What is particularly interesting about the children's errors is that they did not begin to occur as soon as the child had both the word used wrongly and the word called for by the context in her active vocabulary; weeks or months of essentially correct usage intervened. This suggests that the child was not initially aware of the semantic similarities among the words with which she subsequently made errors. However, at some point during the period of correct usage for particular words a change or restructuring took place such that the semantic similarities became operative. ${ }^{2}$ Following this shift, the child's intention to express a certain idea apparently called up more than one candidate lexical item from among which a choice had to be made.

If this interpretation of children's lateemerging substitution errors is accurate, the errors reveal some interesting facets of early semantic development. First, they suggest that children begin to draw lexical items into structured semantic systems based on shared meaning components much earlier than many investigators have supposed. Second, the particular errors they make indicate that young children are capable of perceiving surprisingly abstract and subtle semantic similarities among words. Third, certain differences between the children's errors and those made by adults have interesting implications for the development of the ability to plan a sentence to express a certain idea and monitor the adequacy of its execution. These topics are taken up in order.

\section{Building Semantic Networks: When Does It Begin?}

Psychologists have for some time been interested in the question of when the words in children's vocabularies become integrated into a coherent semantic system describable in terms of networks of shared semantic features (e.g., Anglin 1970; McNeill 1966; Miller 1972). On the basis of experimental evidence of various kinds, they have typically concluded that this integration takes place-or begins to

2 The exact nature of this change is unclear, but some possibilities will be considered in the concluding section of this paper. 
take place-relatively late, at about the age of 6-8 (e.g., Anglin 1970; Francis 1972; McNeill 1966)..$^{3}$

The substitution errors to be discussed in this paper indicate that, counter to this assumption, semantic integration can get under way well before the early school years-as early as 2-4 years of age. Differences in methods of data collection may account for this discrepancy in estimates of the age at which semantic integration begins. Past studies have employed tasks such as word association, free recall of lists of words, and sorting and rating of words. To perform on these tasks in a way that demonstrates a sense of semantic structure probably requires certain abilities-such as the ability to retrieve words consciously or to reflect about language-that may mature later than the onset of semantic organization (Mansfield 1977). Mansfield, who tested children with a "false recognition" technique that she judged made fewer cognitive demands than more commonly used tasks, found that even kindergartners (the youngest children she tested) "have well-organized conceptual systems based on shared meaning components" (1977, p. 75). Cramer (1974) obtained similar findings with a false recognition task.

The method used in the present study, the collection and analysis of spontaneous speech errors, has the advantage of placing no demands on the child whatsoever. Thus, the data reflect semantic knowledge that may be completely unconscious and inaccessible "on demand." An additional advantage of the method is that the children demonstrate by their own errors what areas of the lexicon they have semantically integrated at a given time; they are not constrained to provide evidence on only those semantic domains the investigator selects to study. The latter feature of the method is especially important because the errors produced by the subjects of this study are concentrated in semantic domains that have not been the subject of more controlled exploration.

\section{Some Error Data}

Errors with put, give, make, and let.The most dramatic of the children's lateemerging substitution errors involved the interchange of put and give, put and make, and make and let. ${ }^{4}$ These errors did not begin to occur until the children had been using these words in an essentially appropriate way for some time-for over a year, in Christy's case (there are some exceptions for put, to be described in the next section). Examples of these errors are presented in Appendix A, preceded by representative examples of the early semantically correct use of the words. Two examples of the put-make interchange collected from other children are also included to suggest that errors of these types may be rather general. ${ }^{5}$

Why would put-give, put-make, and makelet come to compete with each other for selection in particular speech contexts? Semantic similarities between the words in these pairs have been discussed by several linguists.

Both put and give, in their most basic and usual senses, specify actions in which an agent causes an object to move to a new location (Lyons 1967). Give has further ties to concepts of possession that put does not. However, it has often been hypothesized that possession is defined by young children not in terms of abstract concepts of ownership but on the basis of concrete cues of the physical location and control of objects. Thus, the essential distinction between put and give for children-as Lyons (1967) has in fact argued is also true for adult English-may be simply that give is selected in the event of an animate goal (location to which something is conveyed), while put is selected when the goal is inanimate. Thus, one says "Give the book to Daddy," not "Put the book to Daddy," and "Put the book

3 There is, however, evidence that words in some semantic domains may be seen as semantically related even before their meanings are fully understood (e.g., Bartlett [Note 2] on color terms; see also Clark 1973).

4 In these, as in several other semantic domains, the errors made by Christy and Eva were virtually identical. A "modelling" explanation for the errors of Eva. the younger child, must therefore be considered, but it can easily be ruled out on the basis of the children's age difference, 2\%2 years. By the time Eva began to make certain errors, Christy had typically long since stopped making them. Additionally, Eva's errors, like Christy's before her, were preceded by a period of correct usage. These facts support the inference that Eva's errors were a spontaneous byproduct of her own language processing rather than an effect of Christy's speech.

5 I am grateful to Ginny Gathercole and Mabel Rice for providing me with these and the "other children's" errors in Áppendix B. 
on the shelf," not "Give the book on the shelf."

Put and make also share elements of meaning. According to Binnick (1971), both verbs can be regarded as causative forms of $b e$, with the selection between them in particular speech contexts governed by whether the implicit be is followed by a locative or a stative phrase. Thus, for example, if one wants to express how it came about that a chunk of PlayDoh "is on the table" (a location) one says (e.g.) "I put it on the table," not "I made it on the table." Conversely, if one wants to express how it happened that the Play-Doh "is flat" (a state) one says (e.g.) "I made it flat," not "I put it flat." In many other types of sentences, locative and stative notions are accorded identical structural treatments (e.g., compare the use of the copula be in "It is on the table" and "It is flat"). This has led a number of linguists to hypothesize that locative and stative concepts are organized similarly in cognitive structure (e.g., Anderson 1969; Jackendoff 1976; Talmy, Note 3).

Finally, make and let are similar in meaning in that they are both facets of a superordinate concept of causation. The primary difference between them is that make specifies active causation, in which an entity acts-does something-with the result that some event comes about or is maintained, while let specifies passive causation, in which an entity does not act, likewise with the result that some event comes about or is maintained. Compare, for example, the meanings of the following sentences:

1. Mother made Johnny stay in bed.

2. Mother let Johnny stay in bed.

The similarity in meaning between make and let is attested to by the fact that in many languages causative sentences are created with a causative morpheme that is indeterminate between these two senses (e.g., see Comrie 1976).

The fact that Christy and Eva used put, give, make, and let correctly before the onset of substitution errors, and continued to use them correctly most of the time even during the period of errors, indicates that when the errors started to occur they were not simply due to failure to discriminate between the various meanings. That is, the children clearly saw the difference between animate and inanimate goals, between changes of location and changes of state, and between active and passive causation, and they knew which word was associated with which meaning. Following the model outlined earlier, we can hypothesize that the onset of errors signaled a change or reorganization of some type in the children's mental lexicon such that these word pairs, which were apparently not initially recognized as semantically related, moved closer together in meaning.

More on put and other cause-change-oflocation verbs.-Well before Christy and Eva started to interchange put with give and make, they began to make periodic errors in which put, take, and bring were substituted for each other and for verbs such as drop and make go. Some examples are presented in Appendix B, along with a couple of similar errors from other children to indicate the probable generality of the phenomenon. ${ }^{6}$

All these verbs specify an action which causes an entity to undergo a change of location. They differ from each other, however, in multiple nuances of meaning. For example, bring and take contrast with each other in many contexts in that they specify different directions of movement with respect to the speaker and hearer. The oddity of sentences 9 , 10, 20, and 21 in Appendix B, in which bring and take are interchanged (e.g., "She brought it over there"), stems from violations of directionality. Put contrasts with bring and take in that it can rarely be used in the context of changes of location involving considerable distances, and it implies nothing about direction of motion. Violations of these constraints account for the strangeness of sentence 4, "Yeah, and I didn't put it home," said with reference to a book the child had forgotten to bring home with her. Put also contrasts with bring and take in that the latter two words imply bodily accompaniment in many contexts, while the former does not. Sentence 13, "I take it up," said as the child put a bowl into a cupboard, is thus odd because the use of take would be appropriate only if the child herself were going up with the cup; sentences 12,16 , and 22 are anomalous for a similar reason. Put differs from certain other cause-change-of-location verbs like drop and make go in that it usually implies a deliberate act in which the agent initiates contact with the object moved and maintains this contact until the move is completed.

6 Interchanges of bring and take have been shown to be widespread in children's spontaneous speech (Richards 1976) and so are not documented further here. 
982 Child Development

Sentences 5 and 6 constitute errors because one or both of these conditions is not met.

Christy and Eva used put, bring, take, and other related words like drop accurately for a period of time before they began to make errors in selecting among them. However, these errors began to occur considerably before those involving the interchange of put with make and give, in some cases (especially for bring) after a relatively short period of correct usage. The errors were also much more frequent than those involving put-make and put-give. The earliness and frequency of the errors, relative to those discussed in the preceding section, suggest that the children did not yet quite understand the meanings of the words involved. Further evidence for this possibility comes from Richards's (1976) study of 4-7-year olds' spontaneous use of take and bring in contrived play situations, which showed a complex and changing pattern of mutual substitutions that did not subside until age 7 or beyond. But how can we reconcile the hypothesis that Christy and Eva had not quite worked out the meanings of these verbs with the fact they used them entirely correctly before they began to make errors?

It may be that correct usage can coexist with incomplete semantic knowledge when children do not attempt too much with their words (see Carey [1978] for relevant discussion). Christy's and Eva's first uses of put, take, etc., were restricted to relatively specific, and different, contexts. For example, they initially used put in the context of donning clothing, placing small objects onto surfaces or into containers ("put on," "put in"), returning things to an original location ("put back"), or storing things out of sight ("put away"). In contrast, they used take for the removal of clothing from the body or small objects from surfaces or containers ("take off," "take out"), for requests to be taken outside ("take outside"), and for asking that something be removed or protesting its removal ("take away").

A child who is quite capable of choosing the correct word in contexts like these (no real "choice" may in fact be necessary, since the words may not compete) may be at a loss when she wants to refer to a new act that does not fit clearly into any of these categories, such as sticking her thumbs up (example 15 in Appendix B). Perhaps it is at this point-when the child increasingly wants to encode novel actions that cause an entity to change location -that semantic similarities among words like put, bring, and take begin to be appreciated and the words start to compete for selection in particular speech contexts. At this point the child must begin to attend to semantic nuances of which she may earlier have been unaware, such as whether a word implies deliberateness, bodily accompaniment, or a certain directionality. Only after she has sorted out these details will she be able to make future choices in a semantically principled way.

\section{Planning and Monitoring Speech in Childhood and Adulthood}

This paper has stressed the similarities between the children's substitution errors and those of adults. However, there are two important differences as well, and they appear to be interrelated.

The first difference is one of frequency. Particular substitution errors by adults-for example, contemporary for adjacent-apparently do not occur repeatedly within a relatively short time span. In contrast, many of the children's errors were recurrent, even though infrequent relative to the number of correct uses.

The second difference is in the speaker's propensity to correct errors. Adults often catch and repair their errors in midsentence, although they are not always conscious of having done so (Laver 1973). Christy and Eva, in contrast, seemed insensitive to having made errors. Explicit self-corrections of word choice almost never occurred (example 41 in Appendix A is unusual in this respect). Very occasionally, the children spontaneously followed up a sentence containing an error with a sentence that was identical except that the wrong word had been replaced by the word that was called for by context and/or syntax (e.g., examples 10 and 18 in Appendix A). Paraphrased "corrections" of this sort occurred most often in response to an adult's request for clarification (e.g., 20 in Appendix A). The direction of this paraphrasing was always the same: a correct word always replaced an incorrect word, never the other way around.

Whether or not a speaker makes errors in word choice depends upon how successfully he is able to compare competing lexical items, choose among them, and edit the choice prior to executing an overt motor program for the sentence. And whether or not correction takes place following an error depends on the speaker's ability to monitor his output and detect 
deviations from his intention (motivational factors undoubtedly also play a role). Laver observes that there is "considerable overlap of purpose" between planning a sentence prior to its execution and monitoring it afterward. Both processes involve "continual scrutiny, and, where necessary, revision, to . . . achieve fairly continuously successful linguistic communication" (1973, p. 141). Revisions carried out before the execution of the motor program result in error-free speech, while revisions carried out after the execution of the program result in self-corrections.

It is possible that the process of semantic integration, whereby words not previously seen as related move closer together semantically, puts a new strain on the child's planning and monitoring capacities. Prior to integration in a particular lexical domain, the child's desire to express a given idea may call up only one lexical item; no decisions are required. Following integration, semantically similar lexical items compete and a choice must be made. Lacking experience or skill at making the necessary selection, the child may for a time tend to settle on a candidate word too uncritically. In this case, an interlocutor's request for clarification may lead the child to reevaluate her selection for possible inadequacy and make an amendment where necessary. Alternatively, the errors may occur because candidate words are at first processed too slowly, such that the motor program is carried out before a final choice has been made. In this case the final choice may sometimes be overtly displayed even in the absence of external prodding, in the form of a corrected self-repetition.

\section{Two Final Problems}

In this paper I have presented examples of young children's word-choice errors that did not begin to occur until both the wrongly used word and the word it replaced had been used correctly for some time, and I have argued that existing hypotheses about why children use words incorrectly cannot account for these lateemerging errors. I then proposed that these errors stem from the child's implicit recognition of similarities among the meanings of the words involved. According to this account, the errors do not occur as soon as the words in question enter the child's speech because the child does not yet see them as related. Following some sort of developmental change, however, the words come to compete for selection when the child plans to express a certain idea.

In conclusion, two unresolved problems should be mentioned. First is the issue, alluded to earlier, of the exact nature of this change. Several possibilities can be envisioned. One, for example, is that lexical items that the child eventually will occasionally interchange initially share no semantic features. The errors start to occur when one or more common features are added to the lexical entries for the words. This account of progress (raised as a theoretical possibility by. McNeill [1970, p. 116], who termed it "horizontal" semantic development) does not provide a cogent account of the present data. This is because the child's earlier correct usage requires us to assume that the child in some sense recognized that notions of causation, change of location, etc., are encoded by the words put, give, and so on-but these are precisely the features that the words share and that seem to account for the eventual competition among them.

A second possibility is that the onset of errors does not stem from the child's having added something qualitatively new to her lexical entries but, rather, from her having implicitly compared the contents of her existing entries and recognized that some of the meaning components are the same (McNeill's [1970] "vertical" semantic development). This account is appealing but requires some further work to be made compelling. In particular, some explanation must be found for why identical components are not at first recognized as such. One line of thinking about this is suggested by Bowerman (1974) and Carey (1978). In these studies it is proposed that, although children initially may have a general conceptual understanding of the kinds of contexts in which particular words are appropriate, they have not yet isolated those aspects of the contexts that are of particular linguistic significancethat serve as semantic features or "lexical organizers" (Carey's term) across a number of words in the same lexical domain. According to this account, an important facet of early semantic development is the child's gradual abstraction of those elements of the meanings of individual words-for example, "cause" and "change of location"-that serve to structure lexical domains taken as a whole.

A second issue in need of exploration is whether semantic integration proceeds differently for words of different types. This possi- 


\section{Child Development}

bility is raised by the fact that almost all the substitution errors made by the children studied here-and all the recurrent ones-involved verbs and other relational words such as prepositions and adjectives rather than nouns labeling concrete objects. This asymmetry in the distribution of errors may be a function of the order in which semantic integration occurs for different words: children may come to appreciate semantic similarities among relational words earlier than among words of other kinds. Gentner's (this issue) arguments about the differences between relational words and concrete nouns suggest a possible reason for such a progression. According to Gentner, the components of verbs and other relational words are "both less redundant and less densely interrelated than those of simple nouns." If true, this suggests that it should be easier for a child to tease apart the important meaning elements of relational words and recognize them as having recurrent organizational significance than to perform these analyses for concrete nouns.

Alternatively, however, there may be no systematic difference in the time at which the semantic analysis and interrelating of words of different kinds get under way. In this case, differences in the extent to which children make substitution errors with relational words versus with concrete nouns might stem either from differences in the extent to which semantically related words of these types are "activated" by the intention to express given ideas or from differences in the relative efficiency with which children compare and select among competing words of different kinds. Evaluating these alternative explanations will require further research.

\section{Appendix A}

\section{Correct and Incorrect Uses of Put, Give, Make, and Let $^{7}$}

\section{Examples of Initial Correct Usage for All Four Words}

A. Put

1. C (about 2-0): Marc mommy put Christy pant away?/Christy put away nipple/I put money light/ I put it somewhere/Mommy got up couch, put glasses on/I put this mine bed with $\mathrm{me} / \mathrm{Put}$ she right there.

2. E (1-11 to 2-0): Christy won't put on her hat/Christy put that thing in she's mouth/Lemme put it B. Give [sweater] on.

3. C (2-0 to 2-3): Gimme more gum/Mommy gimme dolly/Grandma gimme Christy dolly/Daddy gimme Mommy milk (gimme as monomorphemic unit)/I give wow-wow something eat/Mommy give my $[=\mathrm{me}]$ a big bite/Daddy give my $[=\mathrm{me}]$ a kiss/Give Daddy black one.

4. E (1-11 to 2-0): Daddy gave my lady bug to me/Santa Claus give candy to me/Linda gave my C. Make $[=\mathrm{me}]$ choo choo train/I give my chocolate pudding daddy.

5. C (2-0 to 2-3): I make back wet/I make it full/Make cow fix/It could make me sneeze/NP makes me cough/And I made Marc cry.

6. E (1-11 to 2-0): Make feel better my thumb/Make all clean/Make it standing up/I can't make D. Let standing up/Make fall down/Christy make my bonk feel better.

7. C (2-1): Let Christy rock me by self/Let me bring her/Let me put my jacket on myself/ Let me Mommy get in here (= let Mommy; Let me as a unit).

\section{Examples of Incorrect Usage}

A. Put substituted for give

8. C (3-3): You put me just bread and butter. (Request for $\mathrm{M}$ to give it to her.)

9. C (3-4): $\quad$ You put the pink one to me. (Request for M to give her the pink one of two cups.)

10. C (3-4): Put Eva the yukky one first. Give Eva the yukky one first. (Wants $M$ to give $\mathrm{E}$

11. C (4-3): the bad-tasting medicine before the good-tasting medicine.)

11. C (4-3): And we putted the orange juice to Tabby and Benji and me and Eva. (Reporting

12. E (2-2): $\quad$ I go put it to Christy. (Starting off with a rubber band, then gives it to $C$.)

13. E (2-4): Can I go put it to her? (Then takes juice and gives it to C.)

${ }^{7}$ Here and in Appendix B, C $=$ Christy, $\mathrm{E}=\mathrm{Eva}, \mathrm{M}=$ Mother, and $\mathrm{D}=$ Daddy. 

14. $E(2-4)$ :
M: It's all gone. (Re: C's juice.)
15. E (2-4):
$\mathrm{E}$ : Then put her some more.
16. E (2-4):
How come you're putting me that kind of juice? (As M prepares to give unfamiliar juice to E.)
We're putting our things to you. (To D, after $M$ has told children that it's time to give him their Father's Day presents.)

B. Give substituted for put

17. C (4-1): Whenever Eva doesn't need her towel she gives it on my table and when I'm done

with it I give it back to her.

18. E (2-7): Give some ice in here, Mommy. Put some ice in here, Mommy. (Pointing to ice

19. E (2-9): crusher.)

20. E (2-10): I'm gonna give your glasses right here. (M: Huh?)

21. E (2-10): Don't give those next to me. (As C dumps things on couch near E's seat.)

C. Put substituted for make

22. C (3-1): You put a place for Eva to put in. (Wants $M$ to make a depression in a pillow in

doll carriage, so $\mathrm{E}$ can ride.)

23. C (3-9): $\quad$ But never ever put the door locked. (Scolding M.)

24. C (4-3): I putted part of the sleeve blue so I crossed it out with red. (Telling M about mistake in drawing.)

25. C (5-4): I put it brown. (After colors skunk's stripe brown.)

26. E (2-10): I want to put it tight. (Wants $\mathrm{M}$ to let her tighten nipple on her bottle.)

27. E (3-0): ( $\quad$ has instructed $M$ to draw a girl):

$\mathrm{M}$ : You mean put her on this same page?

28. E (3-10): They put Dorothy different than in the book. (After watching a show on "The They put Dorothy different than in the book. (After watching a show on "The
Wizard of Oz" on TV.)

29. E (4-7): I'm not going to put it too long. (E cutting pieces of yarn for a doll's hair.)

30. Rachel (4-11): I already put a list of who I want to come. (Telling grandmother on phone that she's made a list of guests for her birthday party.)

D. Make substituted for put

31. E (2-2): I make some butter my sandwich. (As E puts butter on bread.)

32. E (3-0): $\quad$ Make them back up. (Wants $\mathrm{M}$ to put/set tiny dolls back onto coffee table; they'd

33.

33. E (3-0): Don't take these apart 'cause I'm gonna make these ... on this. (Warning M not

34. Mindy (6-1): I wanta make my shoes in order. (Lining up shoes in closet.)

E. Let substituted for make

35. C (3-3): I don't want Sandra to say good night. So don't let me. (Doesn't want visitor to

come into her room at bedtime. Protesting to M.)

36. C (3-6): I don't want to go to bed yet. Don't let me go to bed. (After M has told her she

37. $C(3-8)$ must go to bed.)

37. C (3-8): How come you always let me wear those? (As M puts C's shoes on; she wants to

38. C (3-8): If you want to see it I'll let you. If you don't want to see it I won't let you. (Re:

39. C (3-11): Don't ever ever let me stay in my bedroom until I go to bed. (As M starts getting

40. C (4-1): I ready for bed without officially ending, C's stay in her room for naughtiness.) gets sent to her room for naughtiness.)

F. Make substituted for let

41. C (3-6): But usually puppets make-let people put their hands in. (After M had called dolls

with toilet paper roll bodies puppets; C disagreeing.)

42. C (3-9): Make me watch it. (Wants D to let her watch a TV show. She used let appropriately in this context shortly before.)

8 These examples of substitutions involving make and let are all from Christy. She made this particular type of error much more frequently than Eva, although Eva's were patterned in the same way. 


\section{Child Development}

\section{Appendix B}

\section{Substitution Errors Involving Put, Take, and Bring}

A. Put substituted for take, bring, drop, make go

1. C (2-2): I I haffa put these off so me can do it better. (Trying to take rings off her fingers.)

2. C (3-1): I I wanta put it off. (Taking coat off.)

3. E (2-1): I'll go put rubber band off. (Starting to take rubber band off deck of cards.)

4. E (2-3): M: Did you leave a book over there?

$\mathrm{E}$ : Yeah, and I didn'i put it home. (About a book she didn't bring home from sitter's house.)

5. E (2-1): I put those way down there. (After drops two Kleenexes on the floor from her high chair.)

6. C (3-8): $\quad$ You put me forward a little bit. ( To $M$, after $M$ jerks car while driving, making $C$ go forward.)

7. Jaime (4-11): Put my hand out. (Take. After gets hand caught in mouth of piggy bank.)

8. Mindy (6-0): You said what I was going to say ... put the words right out of my mouth. (Took.)

B. Take substituted for bring, put

9. C (2-2): Hey, I take this at home. (Finding doll she had brought home earlier.)

10. C (3-7): $\quad T a k e$ it to me. (Wants E to bring a toy to her from across the room.)

11. C (2-1): Daddy take his pants on. (Put.)

12. C (2-3): I Iaffa take this in. (Putting doll's dress into pocket of doll's apron.)

13. E (2-0): I take it up. (Putting bowl up onto shelf in cupboard.)

14. E (2-3): I'm gonna take your nose on. (Pretending to put M's nose back on.)

15. E (4-2): After I do that I take them up again like that. (Showing $M$ how she puts her

16. $E(4-6)$ thumbs up after concealing them under her hands in her lap.)

I took it down the slot. (After E puts a scrap of paper into car ashtray.)

17. E (4-6): She's taking it on! (Upset when a friend is putting E's floatie [a lifesaving device]

18. $E(4-9)$ : on her arm.)

You better quit it! Don't take your feet over on my side! ( $\mathrm{E}$ and $\mathrm{C}$ in bathtub together; C has put her feet into E's territory.)

C. Bring substituted for take, put

19. C (2-1): Let bring this out. (Wants to take cooked bacon out of pan on stove.)

20. C (3-4): $\quad$ She brought it over there. (Watching dog take food into adjacent room.)

21. E (2-9): $\quad$ I'm gonna bring this outside. (Planning to take a toy outside. To M, who is inside with her.)

22. E (2-9): I'm bringing it back to my pocket. (Putting a piece of gum back in her pocket.)

\section{Reference Notes}

1. Bowerman, $M$. The structure and origin of semantic categories in the language learning child. Paper prepared for Burg Wartenstein Symposium no. 74, Fundamentals of Symbolism (Wenner-Gren Foundation for Anthropological Research), Burg Wartenstein, Austria, July 1977.

2. Bartlett, E. J. Semantic organization and reference: acquisition of two aspects of the meaning of color terms. Paper presented at the biennial meeting of the Society for Research in Child Development, New Orleans, March 1977.

3. Talmy, L. Semantic structures in English and Atsugewi. Unpublished doctoral dissertation, University of California, Berkeley, 1972.

\section{References}

Anderson, J. The case for cause: a preliminary inquiry. Journal of Linguistics, 1969, 6, 99-104.
Anglin, J. M. The growth of word meaning. Cambridge, Mass.: M.I.T. Press, 1970.

Binnick, R. I. Studies in the derivation of predicative structures. Papers in Linguistics, 3, nos. 2 and $3,1971$.

Bloom, L. One word at a time: the use of singleword utterances before syntax. The Hague: Mouton, 1973.

Bowerman, M. Learning the structure of causative verbs: a study in the relationship of cognitive, semantic, and syntactic development. Papers and Reports on Child Language Development (Stanford University), 1974, 8, 142-178.

Bowerman, M. Semantic factors in the acquisition of rules for word use and sentence construction. In D. M. Morehead \& A. E. Morehead (Eds.), Normal and deficient child language. Baltimore: University Park Press, 1976.

Bowerman, $M$. The acquisition of rules governing "possible lexical items": evidence from spontaneous speech errors. Papers and Reports on 
Child Language Development (Stanford University), 1977, 13, 148-156.

Bowerman, M. The acquisition of word meaning: an investigation into some current conflicts. In N. Waterson \& C. Snow (Eds.), The development of communication. New York: Wiley, 1978.

Carey, S. The child as word learner. In M. Halle, J. Bresnan, \& G. A. Miller (Eds.), Linguistic theory and psychological reality. Cambridge, Mass.: M.I.T. Press, 1978.

Clark, E. V. What's in a word? On the child's acquisition of semantics in his first language. In $\mathrm{T}$. Moore (Ed.), Cognitive development and the acquisition of language. New York: Academic Press, 1973.

Clark, E. V. Knowledge, context, and strategy in the acquisition of meaning. In D. Dato (Ed.), Georgetown University round table on languages and linguistics. Washington, D.C.: Georgetown University Press, 1975.

Comrie, B. The syntax of causative constructions: cross-language similarities and divergences. In M. Shibatani (Ed.), Syntax and semantics. Vol. 6. The grammar of causative constructions. New York: Academic Press, 1976.

Cramer, P. Idiodynamic sets as determinants of children's false recognition errors. Developmental Psychology, 1974, 10, 86-92.

Fay, D., \& Cutler, A. Malapropisms and the structure of the mental lexicon. Linguistic Inquiry, $1977,8,505-520$.

$\rightarrow$ Francis, H. Toward an explanation of the syntagmatic-paradigmatic shift. Child Development, 1972, 43, 949-958.

$\rightarrow$ Fromkin, V. A. The non-anomalous nature of anomalous utterances. Language, 1971, 47, 27-52.
Fromkin, V. A. (Ed.). Speech errors as linguistic evidence. The Hague: Mouton, 1973.

Huttenlocher, J. The origins of language comprehension. In R. L. Solso (Ed.), Theories in cognitive psychology: the Loyola symposium. Potomac, Md.: Erlbaum, 1974.

Jackendoff, $R$. Toward an explanatory semantic representation. Linguistic Inquiry, 1976, 7, 89150.

Laver, J. D. M. The detection and correction of slips of the tongue. In Fromkin 1973.

Lyons, J. A note on possessive, existential, and locative sentences. Foundations of Language, 1967, 3, 390-396.

McNeill, D. A study of word association. Journal of Verbal Learning and Verbal Behavior, 1966, 5, 548-557.

McNeill, D. The acquisition of language: the study of developmental psycholinguistics. New York: Harper \& Row, 1970.

Mansfield, A. F. Semantic organization in the young child: evidence for the development of semantic feature systems. Journal of Experimental Child Psychology, 1977, 23, 57-77.

Miller, G. A. English verbs of motion: a case study in semantics and lexical memory. In A. W. Melton \& E. Martin (Eds.), Coding processes in human memory. New York: Wiley, 1972.

Nooteboom, S. G. The tongue slips into patterns. In A. G. Sciarone, A. J. Van Essen, \& A. A. Van Raad (Eds.), Nomen: Leyden studies in linguistics and phonetics. The Hague: Mouton, 1969. Reprinted in Fromkin 1973.

Richards, M. M. Come and go reconsidered: children's use of deictic verbs in contrived situations. Journal of Verbal Learning and Verbal Behavior, 1976, 15, 655-665. 